\title{
The Dream as Foetus
}

\author{
Kurt Forrer* \\ Maldon Victoria, Australia \\ *Corresponding author: Kurt Forrer, 26 Parkins Reef Road, Maldon Victoria 3463, Australia \\ To Cite This Article: Kurt Forrer, The Dream as Foetus. Am J Biomed Sci \& Res. 2020 - 7(2). AJBSR.MS.ID.001122. \\ DOI: 10.34297/AJBSR.2020.07.001122.
}

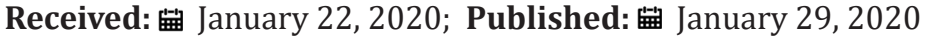

\begin{abstract}
Nanshe, the Babylonian Goddess of dream interpretation is at the same time the Goddess of water and fertility; "her symbol a vessel with water and a fish in it, symbolising her gravid womb". There is no better support of such a view than a woman's dream announcing her pregnancy by means of a fish floating in her swimming pool. The symbol for Nanshe testifies to the Babylonian's perfect understanding of the pathway and function of the dream. Today dreams are generally disregarded, but when a nightmare disturbs us and when in the end we realise that it disappears when it is understood, we see that dreams influence waking life.
\end{abstract}

Nanshe's fishbowl has its counter part in the Vesica Piscis, 'vessel of the fish'. It was an unequivocally genital sign of the sheila-na-gig figures of old Irish churches. While Nanshe's fishbowl represents the gravid womb, the Vesica Piscis stands for the birthing process. Nanshe and her fishbowl are also associated with an Abyss or Abaton. Also called a mundus or earth-womb, the Abaton was a real pit, standard equipment in a pagan temple. Those who entered it to 'incubate', or to sleep overnight in magical imitation of the incubatory sleep in the womb, were thought to be visited by an 'incubus' or spirit who brought prophetic dreams. Nanshe's priests underwent a death and resurrection ritual by descending into the pit in order to emerge as qualified dream interpreters.

In our non-theistic psychology this pit has become the Unconscious, which Freud saw as the receptacle of our total destiny. Just as the foetus embodies a future human being, so the dream encapsulates what is to occur in waking. Our forebears of Nanshe's days would insist that the dream outlined both the subject's constitution and its concomitant environment. Current science accepts this only in as much as the DNA of the foetus determines the future evolution of the physique and mind, but not the life path.

A modern equivalent of descending into the pit is being struck down by a serious disease that causes a change of attitude to life. The extreme case is the NDE, which gets the subjects in touch with the transcendental world and changes their outlook on life and endows them with a new view of dreams, part of which is an understanding that they are messengers of the future.

The Kundalini experience is a sister experience of the NDE. Kunda is a sacred pit for fire worship, but it also links up with the base of the spine where the Kundalini resides in the human body and gradually rises to the top of the skull either at death of the body or death of the ego. Pam Reynolds' NDE case demonstrates that the Hindu lore of chakras is fact not fiction.

Keywords: Abaton; Shamanism; Abyss; Unconscious; Chakras; Vesica Piscis; Foetus; Kundalini; NDE

\section{Introduction}

Nanshe, the Babylonian Goddess of dream interpretation is at the same time the Goddess of water and fertility; "her symbol a vessel with water and a fish in it, symbolising her gravid womb". [1] Indeed, like a fish, the foetus swims in the amniotic fluid of the womb, and like a foetus, the dream germinates in an internal world.

There is no better support of such a view than a woman's dream announcing her pregnancy by means of a baby floating in her swimming pool. Yet a more frequent sign of her pregnancy is a dream of fish. Here, like always, the context is of prime importance, for a fish in a particular scenario may simply stand for the penis, as in a dream of a woman, for instance, where she is grasping a fish. On the other hand, a dream of an aquarium full of fish would be more certain to foretell a pregnancy. Such a dream will not only alert the woman to the fact that she is pregnant but will at the same time also indicate whether or not the occasion would be welcome. The latter will obviously become evident in her reaction to her dream.

I know of a case where a young woman, just recently married, recalled just such a dream. She described the beauty of the fish in 
glowing terms, relishing their colours and exquisite patterns. The upshot was, of course, equal excitement at the arrival of a healthy boy.

The symbol for Nanshe testifies to the Babylonians' perfect understanding of the pathway and function of the dream. It clearly makes evident that the land's priesthood understood that the dream was the germ for corresponding waking situations and events. It explains in one simple picture that the dream engenders an internal world, which like a germ is a rudimentary and compact potential that will develop to its concisely described fullness upon passing into the external, waking world. In other words, just as a foetus is more of an indication what will be, so the dream in its elemental form merely suggests what the fully matured waking counterpart might look like and how its condensed drama might unfold.

It is mostly because of the dream's 'foetal form' and compactness that the uninitiated finds the dream a most bewildering experience. "I've had a weird dream" is a common exclamation. The nocturnal dream experience is found to be such because it usually does not align with 'common sense' scenarios and sequences. Situations look bizarre and surreal. Surreal is, of course, a most apt term for the dream because it is 'sub waking reality'. It underlies all of what is happening on the waking surface. This sub-fact, acknowledged in the term 'surreal' ought to make us stop and think about the role of the dream in that position. Does it not intimate that the dream might well be the foundation of the waking experience?

Generally, the circumstance that the dream is in a sub position earns itself an inferior status. It is looked down upon and considered something of lesser importance than what is above it. It is like forgetting that the ground we stand on is also the substance and framework of our physical bodies. "Earth produces food", so we say, but more often than not we call it 'dirt', forgetting that we eat it in its transmuted state, so nourishing and building our very body.

This is often the stance we assume when we are confronted with the dream experience. "Just a bit of weird surrealism of no consequence", we might remark. But when in time we realise that nightmares cease at the moment we have understood them, it will dawn on us that dreams must have a wider influence on the waking process than what the first encounter with a nightmare permits us to see. Indeed, upon reflection we may even get to appreciate the fact that such disturbing dreams not only affect our wellbeing when they occur, but that they also must have a distinct directing function since they ultimately lead to the termination of their traumatic disturbances.

The classic example for this fact is the nightmare Michael Barnsley had. It began in his student days and only stopped twenty years later when a more begnine dream showed him that the task the nightmare had assigned to him was to invent image compression software. Curiously enough, his nightmare had withheld its ultimate aim and kept the circuitry for the software secret till the day of the resolving dream. [2] As it turned out later, it had held its aim back because a certain computer program had to be devised first, without which the resolving dream could not have been understood and practically exploited.

Barnsley's nightmare and its resolution in a new invention not only sheds light on the function of nightmares, but also demonstrates that the dream state is in charge of the inventive process; that it knows where it is heading even when the dreamer himself has no inkling of it. There is no better and more convincing case that demonstrates the guiding principle of the dream. (For a full exposition of this theme see my essay online, "To what extent does the dream influence the creative process? IJoDR, University of Heidelberg, Germany)

In light of this, we are compelled to see the source of Nanshe's symbolic fishbowl as an invention of the dream itself. In other words, it was the dream that likened its function to a vessel containing a fish, thus symbolising the more organic situation of a pregnant womb. From this we must conclude that dreaming is a thoroughly feminine matter. Indeed, the sleeping body of the dreamer becomes the womb itself in which the foetal dream world unfolds, and as the sleeper awakes, the birthing process begins, bringing forth a completely new world, perfectly analogous to the birth of a completely new being.

For some, this comparison may seem somewhat contrived, but when we reflect on the waking process a little, we soon see that it is not at all as abiding as it generally impresses us. Matter, as constant as it may seem to our eyes is in permanent flux much like a river, and so, upon waking, we can never step into the same world twice, just as we never can step into the same river twice, or more precisely, into the same mass of water. In other words, as suggested, every awaking is a new birth of the 'nocturnal foetus' that begins its daytime unravelling with the end of the last dream.

Nanshe's fishbowl has its counter part in the Vesica Piscis, 'vessel of the fish'. Its design is that of a pointed oval resulting from the intersection of two circles. It represents the vulva of various Mother Goddesses including that of Mary, Mother of Christ. It is called the 'vessel of the fish' because it is said that the vagina has a 'fishy smell', which description became, in fact, the name of the Hindu Goddess Kali in her aspect as the virgin [3].

"The Vesica Piscis was an unequivocally genital sign of the sheila-na-gig figures of old Irish churches. The squatting naked Goddess displayed her vulva as a vesica as did the temple-door images of Kali in India" [4]. So, while Nanshe's fishbowl represents the gravid womb, the Vesica Piscis stands for the birthing process, the departure of the newly formed being from the inner world in order to grow in the outer realm. And parallel to this, the same vessel stands for the emergence of the dream in order to be transformed to a waking reality. 
The worship of Nanshe continued well into the Christian era, overlapping with it for a considerable time. So it is not surprising that Christians adopted the Vesica Piscis for their own icon, especially in view of the fact that the Greek acrostic for 'Jesus Christ, Son of God the Saviour' resulted in the word FISH.

As this renewed icon, where a transcendental entity is conceived in a virgin's womb in order to become a being of the waking world, the vesica is given a further dimension. It reminds us of the fact that biblical dream interpretation maintains that dreams are unalterable instructions from God [5] Just how this plot of a Saviour in fish gestalt is engrained in our psyche, becomes clearly evident in the fact that the Avatar and Saviour of Vishnu is not only a fish, but emerges from the mouth of a fish [6]

In this context it is of interest to discover that the ancient Egyptians said "Abtu, the Abyss, was a 'fish that swallowed the penis of Osiris', but that abyss was also 'The Fish of Isis', therefore a sexual metaphor" [7] Such erotic mythology of the ancients recalls the fact that for Freud the meaning of the dream was not exhausted until it revealed its sexual sense. For Jung, on the other hand, the critical meaning was in its spiritual associations. The views of both interpreters taken together bring back the full perspective of the ancients. In other words, their understanding of intercourse between man and woman was at the same time also intercourse between heaven and earth. This is not so surprising when we remember that the mystics were not at all averse to speak of the love for God in erotic terms.

With this the cycle and function of the Vesica Piscis is complete. Conception and birth are exposed and with it a further parallel to the dream cycle is made manifest. This is the fact that dreaming and waking constitute a round like breathing in and out. While on the one hand the dream is transmitting new adventures from beyond, some of the waking experiences are fed back into the womb of dreaming. This is parallel to the creative formula of the Mandelbrot set where infinite iteration occurs. Quite generally, the dreaming/ waking round agrees with Einstein's formula that describes energy converting to matter, or dream energy to waking matter.

If we now return to the Egyptian Abyss or the Fish of Isis, we find that Nanshe and her fishbowl are also associated with an Abyss or Abaton. "Also called a mundus or earth-womb, the Abaton was a real pit, standard equipment in a pagan temple. Those who entered it to 'incubate', or to sleep overnight in magical imitation of the incubatory sleep in the womb, were thought to be visited by an 'incubus' or spirit who brought prophetic dreams" [8].

Just as biblical authors saw the dream being transported by an angel, so the priests of Nanshe conceived of the dream's vehicle as a spirit. In both cases the dream is seen to have originated in a transcendental realm, while the earth womb pictures an augmented womb, or an enlarged sleeping body made from earth.
In our non-theistic psychology this pit has become the Unconscious, which Freud saw as the receptacle of our total destiny. As he states in the final chapter of his 'Psychopathology', "all examples imply that both the conscious and unconscious life is determined absolutely" [9].

Priests of Nanshe would agree with this without reservation. Curiously enough, Freud never believed that the dream could give us knowledge of the future, insisting that it was, instead, giving us knowledge of the past [10] It makes us wonder why he never sought to reconcile his findings of his research in psychopathology with that of dream analysis of which he said that it was the Royal Road to the Unconscious. Surely, if psychopathology shows that all is determined, the Royal Road to the Unconscious must inevitably lead us to the same conclusion, from which follows that dreams must be messengers of the future.

Indeed, just as the foetus embodies a future human being, so the dream encapsulates what is to occur in waking. While current science would accept this only in as much as the DNA of the foetus determines the future evolution of the physique and mind, but not the life path, our forebears of Nanshe's days would insist that the dream outlined both the subject's constitution and its concomitant environment.

A good example for this is Gilgamesh's dream which promised victory over Humbaba, the monster guardian of the Lebanese forest where he and his companion Enkidu were to cut the cedar for the royal palace: "In my second dream again the mountain fell, it struck me and caught my feet from under me. Then came an intolerable light blazing out, and in it was one whose grace and his beauty were greater than the beauty of this world. He pulled me from under the mountain, he gave me water to drink and my heart was comforted, and he set my feet on the ground." [11]

The mountain that fell on Gilgamesh's feet was, of course, a reference to the mountainous monster guardian, while the bright light Saviour was Shamash, the Sun God. As for the rest, this dream story is also its interpretation. Enkidu, Gilgamesh's companion rightly confirms this when he says: "Your dream is good, your dream is excellent, the mountain which you saw is Humbaba. Now surely, we will seize and kill him, and throw his body down as the mountain fell on the plain". (Ibid)

This example demonstrates that the dream in the view of our ancestors predicted complete events where there was no room for 'free will'. But this example demonstrates as well that the interpreters of Nanshe's days also understood what I have called associative manifestation or ego-transference. The present case in question is the inversion of Humbaba falling on Gilgamesh's feet in the dream; while in waking Humbaba's body is thrown down on the plain by Gilgamesh (and his companion). 
This example alone is sufficient evidence showing that the Sumerians and their Babylonian heirs understood the function and structure of the dream better than most present day dream researchers do. Of course, there are standardised dream dictionaries of Babylonian extraction inherited by the Roman interpreter Artemidorus, for instance, which indicate that their fixed meanings listed could be misleading. But if we can go by Artemidorus himself, it quickly becomes evident that a good diviner took into account the current, personal circumstances of the dreamer before he ventured a prediction, and thus individualised the standard meaning listed [12] Another thing that needs to be considered is a certain amount of corruption occurring in the course of time.

One aspect current dream researchers often neglect completely is the close connection between dreaming of the future and the Near Death Experience. Most authors of NDE reports maintain that aftereffects of NDE episodes feature an increase in dreams, or to put this more correctly, an increase of dream recalls. Yet a further aftereffect is that the NDE subjects find to their astonishment that their dreams are all of the future. Part of this discovery is that they now have the gift of clairvoyance and precognition [13] Both of these phenomena are, of course, rooted in dreams. Thus, clairvoyance and precognition, which are principally identical occurrences, are simply cryptomnesic recalls of dreams, all of which are inevitably of the future [14]

Earlier on we have seen that Nanshe's fishbowl was associated with an earth womb in which incubation of dreams was sought. For Nanshe's priests it served that very purpose, but for novices it was also an initiation ritual of "descent into the 'pit', a symbolic death and resurrection" [15] Obviously its purpose was to endow the novices with the gift of interpreting the dreams of other men and women.

We discover here an interesting parallel between the Near Death Experience and that of the death and resurrection ritual. In one case we note that there is an increase of dreams that moreover see the future, while in the other we find that the 'resurrected' candidates have now the ability of interpreting the future consequences of dreams.

As well as that, we note that both the NDE and the initiatory ritual clearly end in rebirth, a second emerging from the womb that transforms the 'foetus' and gives it a new ability in life. In fact, the connections between the two situations are close enough for us to suspect that the death ritual could well have its origin in a Near Death Experience.

Certainly, being struck down by a severe and life-threatening illness is often part of a spontaneous initiation into Shamanism. For the 'born Shaman' such illness is transformative. He or she becomes a new 'foetus' as it were, one that will grow into a completely new being with visionary and healing qualities, diminished ego and a totally new world perspective. The parallels between the NDE and be- ing struck down by such life-changing illness are clearly apparent. Indeed, as an author on Shamanism once remarked: "For Shamans, death shows up as a spiritual being, an ever present spirit teacher-guide whom you get to know, and eventually integrate with. It is an on-going relationship" [16]

Of interest in connection with the resurrection from a pit is the lore of Kundalini. The root of this word is Kunda, a sacrificial fireplace in form of a pit [17] Kun is the Earth; the K refers to a hollow, an aperture, which is often symbolised by a yoni or an open vagina. In light of this it would seem that Kunda is the root of the English vulgarism of 'cunt'. Certainly, the vagina as pit of transformation leads us directly to the womb where the foetus awaits its birth.

In chakra lore, Kundalini is said to be at the base of the spine in the genital area. It is pictured as a serpent, which is, of course, a representation of the life force; of energy that gradually spirals along the spine towards higher chakra centres. Literally, chakra means wheel or circle. In chakra lore it is seen as a centre of whirling energy. The higher Kundalini rises, the closer is the individual to enlightenment.

The top chakra is called Sahasrara or crown chakra, symbolised as a thousand-petalled lotus. It is also associated with death. And indeed, enlightenment is a particular death, the death of the ego. But it is also concomitant with the death of the body. There is no better evidence of this than Pam Reynolds' artificially induced death from which she emerged after an hour alive and well. As her body reached hypothermic arrest, her etheric or soul left her body through the top of the skull, so affirming the ancient Hindu wisdom that sees Sahasrara as portal to the transcendental world [18]. There are seven chakra centres in all. But since Sahasrara is the portal to the transcendental world and thus well above the six other centres, much as the Sun is among the seven classic planets (Sun, Moon, Mercury, Venus, Mars, Jupiter and Saturn) it is truer to life to say that there are six plus one chakras rather than seven. [19] Indeed, if we consider the diagram of the 'Seed of Life', the six plus one in place of seven is graphically enhanced. This diagram is constructed by drawing a circle, which represents the realm of creation. Within it are drawn seven overlapping circles with the same diameter. Six of them are regularly spaced within the seventh, producing a rosette with eighteen lens shaped petals: six smaller ones inside and twelve larger ones outside. (Ibid) Each of these lens shapes can quite rightly be regarded as a Vesica Piscis, a birth-giving yoni.

Incidentally, this six plus one relationship alerts us to the fact that the biblical creation story with six days of activity and one day of rest was not to be understood literally, but instead, in terms of mathematical ratios, the ratios of life. But above all, it explains the special position of Sahasrara in Kundalini lore.

As Kundalini reaches Sahasrara we are face to face with the microcosmic counterpart of the annihilation of the old world making 
way for a new creation. Death and rebirth in the Abaton is its parallel. And indeed, we need not dig a pit in the earth at all in order to descend in it for the purpose of life changing transformation, for the human body is a ready-made Abaton in which death and rebirth is constantly re-enacted as immersion in sleep endowed with dreaming that comes to fruition in its subsequent waking manifestation.

Certainly, apart from daily little deaths and revivals that enhance our psyche, there are on occasions transformations of such momentous proportions that they stand out like a rite of passage with effects that are in the league of NDEs. One example is the encounter of transcendental light between dreams. In other words, it is possible to 'wake up' to the cosmic consciousness that underlies our waking and dream states, which is normally hidden by overlaid dream and waking imagery.

Western dream research is not aware of this, so far as I can assess. On the other hand, Hinduism has always been cognisant of it. It claims that in deep sleep, which for the West is delta sleep, it is possible to experience this cosmic consciousness in form of radiant light, the same that NDE subjects report after they have passed through the realm of darkness.

I can vouch for the veracity of this claim thanks to personal experience. In a dream I was led to a temple in which a tiny yogi in padmasana reached out to me as I approached him. He touched my forehead with his finger. I swooned instantly. All thought and imagery vanished, making way for blissful, pure and amazingly bright light.

It can also happen that the dream itself will provide the Abaton in which an oneiric death and resurrection will take place. In such a dream I once was whisked into the womb of Persephone who was emerging from the ground as the Goddess of spring. In her womb, which was a massive, dark hall I floated in frozen angst just below the ceiling. Soon, a fluorescent disk and a fluorescent swastika appeared in the pitch dark. Not long after that I looked down and discovered a TV set that screened a cartoon-like figure whose eyes were bulging out of their socket like tennis balls. It reminded me of a Zen painting of Daruma. He held a huge sceptre in his hand that was constructed from the axel and wheel of a railway car.

As I gradually woke from this nightmarish dream, I thought I was going to sleep because waking reality seemed so insipid compared with the dream. But, more importantly, I found that this expe- rience had endowed me with a better understanding of my dreams, allowing me to see how the dream story unravelled itself in terms of corresponding waking facts. At the same time, I also recognised that the power of Nanshe is still as present today as it was thousands of years ago. After all, time is an illusion as the mysterium coniunctions, where past, present and the future are all experienced as one single event demonstrated to Carl Jung [20].

\section{References}

1. Walker Barbara "The Woman's Encyclopedia of Myths and Secrets". p. 718.

2. Forrer Kurt (2014) "To what Extent does the Dream influence the Creative Process"? IJoDR 7(1): 90-92.

3. Walker Barbara. The Woman's Encyclopedia of Myths and Secrets pp. 1045.

4. Walker, op. cit. page 1045.

5. "In a dream, in a vision of the night, when deep sleep falleth upon men, in slumberings upon the bed, then he openeth the ears of men, and sealeth their instruction". Job 33/15/16.

6. True Origin of Christian "FISH" Symbol Might Outrage, Shock Jesus Worshippers

7. Walker, op cit. pp. 1045.

8. Walker, op. cit. p. 2.

9. Freud (1975) Octave Mannoni. Rowohlt, p. 80.

10. Freud (2010) The Interpretation of Dreams. Penguin Books, pp. 783

11. NK Sandars. The Epic of Gilgamesh. Penguin Book, pp. 77.

12. Artemidorus (1975) Onerocritica passim. RJ White (Ed.), Noyes Press, pp. 175.

13. Matthew D Dovel The Web: Summary of NDE aftereffects.

14. Forrer K. To Test or not to Test. IJoDR.

15. Walker, op. cit. page 718

16. The Web/Kundalini Teacher.com

17. The Web/Swami Muktananda Saraswati.

18. Forrer K (2015) “Brahman’s Dream”. IJODR 8(2): 164-168.

19. Matthews Christopher (2015) Sacred Geometry.

20. CG Jung (1971) Memories, Dreams, Reflections, Retold by Aniela Jaffé [Ed.]. The Fontana Library, Theology \& Philosophy. p. 327. 